\title{
SOME ASPECTS OF BIOLOGY OF LAMBAK PIPIH FISH (Thynnichthys polylepis) IN BATANGHARI RIVER, JAMBI
}

\author{
Siswanta Kaban* \\ Balai Riset Perikanan Perairan Umum dan Penyuluhan Perikanan, Palembang \\ *wanta_kaban@yahoo.co.id
}

\begin{abstract}
Research on some biological aspects of lambak pipih fish (Thynnichthys polylepis) was carried out in the Batanghari River, Jambi Province. Using the survey method, in March, May, August and October 2015. The station was determined by purposive random sampling which was divided into 3 regions: upstream in Mangunjaya and Puntikalo Villages, Tebo Regency, the middle in Penyengat Kecil and Kunangan Villages, Jambi Municipality and downstream in Sungai Kandis and Muara Sabak Villages. The size of the flat-rolled fish caught ranges from $7.2 \mathrm{~cm}$ in length and weighs 4.5 grams and $26 \mathrm{~cm}$ in weight, 162 grams. The largest length is between $10.1-15.0 \mathrm{~cm}$ totaling 55 heads, while the most weight is $1-30$ grams totaling 52 heads. The relationship between long-weight flatfish follows the equation pattern: $\mathrm{W}=0.013 \mathrm{~L} 2.901$ with a value of $\mathrm{b}<3$. So it can be said that flatslawed fish have a negative allometric growth pattern. Its natural feed consists of macrophytes (water growths) as much as $49.9 \%$ as the main feed. Phytoplankton supplementary feed is $22.6 \%$ (Chlorophyceae 10.4\%; Bacillariophyceae $8.1 \%$ and Cyanophyceae $4.1 \%$, and detritus $17.4 \%$. Additional feed is $0.8 \%$ Protozoa; $0.5 \%$ Rotifera and Crustaceae $0,4 \%$ and the unidentified part was $8.4 \%$. Thus flat or motak fish were classified into groups of herbivorous fish or plant eaters.
\end{abstract}

Keywords: lambak pipih fish; biological aspects; Batanghari River,fish population

\section{Pendahuluan}

Jenis ikan di Sungai Batanghari Jambi berjumlah 130 spesies yang terdiri dari 14 Ordo dengan 43 famili. Jenis yang cukup banyak ditemukan di daerah bagian tengah dan hulu Sungai Batanghari adalah dari famili Cyprinidae seperti ikan kepiat, palau, lambak, lambak pipih, repang , keperas dsb (Kaban el at., 2015). lambak pipih (Thynnichthys polylepis) merupakan ikan rawa banjiran yang tersebar di Sungai Batanghari ikan merupakan ikan yang dominan dan memiliki nilai ekonomi cukup penting khususnya di Danau Teluk Kotamadya Jambi (Nurdawati, 2010). Menurut Nurdawati (2013) ikan lambak pipih merupakan ikan dominan di Danau Sipin Jambi terkhusus pada musim kemarau, karena ikan ini dapat beradaptasi terhadap perubahan kondisi perairan di danau tersebut.

Ikan lambak pipih ini termasuk ke dalam famili Cyprinidae ini bersifat demersal dan potamodromus (Froese \& Pauly. 2015). Di Indonesia keberadaannya tersebar di Pulau Sumatera dan Kalimantan (Kottelat el al., 1993). Ikan lambak pipih mempunyai ciri-ciri morfologi yang mempunyai sisik berwarna putih keperakkan, ukuran panjang lebih besar dari pada ukuran tinggi tubuhnya dengan berbentuk bilateral simetris. Kepala meruncing dengan mulut terletak di ujung kepala atau agak kebawah dan kecil, moncongnya dapat menonjol kedepan, tapi tidak ada bibir atas dan rahang bawahnya (Kottelat el al., 1993).

Untuk pengelolaan ikan yang berkelanjutan dibutuhkan data dasar yang berhubungan dengan aspek biologi seperti halnya ukuran ikan, hubungan panjang-berat, kebiasaan makan dan lain sebagainya. Hubungan panjang-berat ikan berguna untuk pendugaan perikanan (fishery assesment), seperti menentuka biomassa karena pengukuran berat ikan langsung dilakukan di lapangan, sedangkan secara tidak langsung biomassa dapat digunakan untuk 
mengestimasi produksi perikanan (Smith,

Kebiasaan makanan bagi ikan dapat merupakan faktor yang menentukan populasi, pertumbuhan dan kondisi ikan. Mengetahui makanan atau kebiasaan makan satu jenis ikan dapat melihat hubungan ekologi antara ikan dengan organisme lain yang ada di suatu perairan, misalnya bentuk-bentuk pemangsaan, saingan dan rantai makanan (Effendie, 1992).

Penelitian tentang beberapa aspek biologi ikan lambak pipih bertujuan memberi masukkan untuk pengelolaannya dimasa mendatang agar sumberdaya ikan ini tetap lestari di Sungai Batanghari dan DAS (daerah aliran sungai) nya di Propinsi Jambi. Sistem penangkapan yang tidak ramah lingkungan dimana upaya penangkapan yang dilakukan terus menerus akan mengganggu proses rekruitmen karena banyaknya ikan ukuran kecil yang tertangkap.

\section{Bahan dan Metode}

Penelitian dilakukan di Sungai Batanghari, Provinsi Jambi menggunakan metode survey, dilakukan sebanyak 4 (empat) kali pada bulan Maret, Mei, Agustus dan Oktober 2015. Penentuan stasiun ditentukan secara purpossive random sampling yang dibagi atas 3 wilayah yaitu : bagian hulu di Desa Mangunjaya dan Puntikalo, Kabupaten Tebo, bagian tengah di Desa Penyengat Rendah dan Kunangan, Kotamadya Jambi dan bagian hilir di Desa Sungai Kandis dan Muara Sabak (Gambar 2).

Hasil tangkapan nelayan dengan bermacam alat tangkap seperti jaring, tangkul dan jala diukur panjang dan berat tubuhnya. Sebaran ukuran ikan dibagi dalam kelas ukuran panjang dan ukuran berat, disajikan dalam bentuk diagram dan dibahas secara deskriptif kuantitatif. Hubungan panjang-berat dianalisis
1996).

mengikuti hukum kubik yang dinyatakan bahwa bobot ikan sebagai pangkat tiga dari panjangnya yang mengacu pada persamaan dari Effendie (1992) sebagai berikut :

Keterangan :

$$
\mathrm{W}=\mathrm{a} \mathrm{L}^{\mathrm{b}}
$$

$\mathrm{W}=$ bobot ikan $($ gram $)$

$\mathrm{L}=$ panjang ikan $(\mathrm{cm})$

$\mathrm{a}=$ intercept (perpotongan antara garis regresi dengan sumbu y)

$\mathrm{b}=$ koefisien regresi (sudut kemiringan garis) 


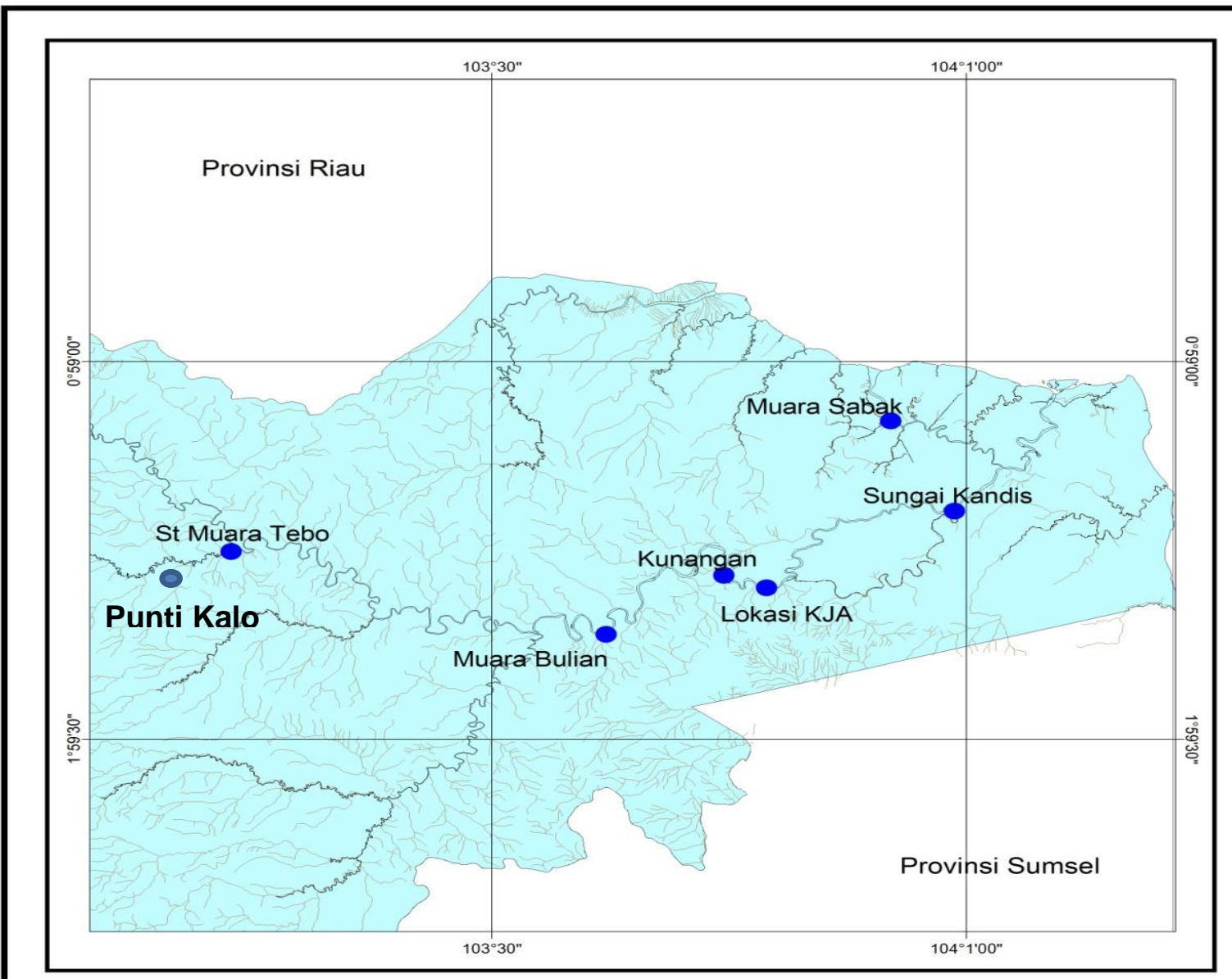

\section{PETA LOKASI SAMPLING}

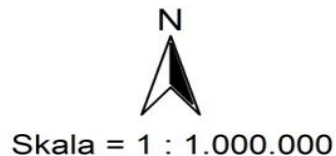

Keterangan :

- Lokasi Pengambilan Sampe Sunga

Gambar 2. Lokasi penangkapan ikan lambak pipih di Sungai Batanghari. 
Nilai b yang didapatkan dilanjutkan dengan uji $t$ (t. tabel) pada tingkat signifikasi $95 \%$. Uji-t : Ho, bila $\mathrm{b}=3$ (isometrik), pertambahan panjang sebanding dengan pertambahan berat. $\mathrm{H} 1$ : $b \neq 3 \quad$ (Allometrik positif/negatif), pertambahan panjang tidak sebanding dengan pertambahan berat.

t hitung $>$ t. tabel = beda nyata (tolak Ho, terima $\mathrm{H} 1$ )

$\mathrm{t}$ hitung $<\mathrm{t}$. Tabel $=$ tidak berbeda nyata (terima Ho, tolak H 1)

Untuk menentukan kebiasaan makan ikan, diambil organ pencernaannya yaitu lambung dan usus. Jenis dan jumlah makanan dianalisis dengan metode indeks bagian terbesar (Index of preponderance) dari Natarajan \& Jhingran (Effendie, 1992)

$$
\mathrm{IP}=\frac{\mathrm{Vi} \times \mathrm{Fi}}{\sum \mathrm{Vi} \times \mathrm{Fi}} \times 100 \%
$$

IP = Index of preponderance

$\mathrm{Vi}=$ persentase volume satu macam makanan

$\mathrm{Fi}=$ persentase frekuensi kejadian satu macam makanan

$\sum \mathrm{Vi} F i=$ jumlah $\mathrm{Vi} \times \mathrm{Fi}$ dari semua macam makanan

Untuk mengidentifikasi makanan yang terdapat dalam usus atau lambung digunakan acuan dari (APHA, 1981; Merrit \& Cummins, 1996; Needham \& Needham, 1962; Pennak, 1978).

\section{HASIL DAN PEMBAHASAN Sebaran Ukuran}

Ukuran ikan lambak pipih yang tertangkap oleh nelayan berkisar antara panjang 7,2 $\mathrm{cm}$ dengan berat 4,5 gram dan $26 \mathrm{~cm}$ dengan berat 162 gram. Ukuran panjang yang paling banyak adalah antara 10,1 - 15,0 cm berjumlah 55 ekor (Gambar 3 / C), sedangkan ukuran berat terbanyak adalah 1 - 30 gram berjumlah 52 ekor (Gambar 3 / A). Ukuran lambak pipih dengan panjang $10,1-15,0 \mathrm{~cm}$ merupakan ukuran yang relatif kecil, biasanya tertangkap dengan beberapa alat tangkap seperti jaring (gill net) ukuran 1 - 1,5 inch, tangkul dan jala. Bahkan tangkul dan jala selain ikan lambak pipih juga menangkap benih-benih ikan dan ikan-ikan ukuran kecil lainnya. Banyaknya ukuran relatif kecil yang tertangkap menunjukkan bahwa ikan lambak pipih ini cukup digemari masyarakat sebagai ikan konsumsi tanpa menunggu ikan ini besar, sehingga masyarakat berusaha menangkapnya dengan bermacam alat tangkap. Namun hal ini dikhawatirkan akan membahayakn kelestarian ikan ini karena tidak sempat menjadi besar dan berkembang biak. Menurut Asyari \& Fatah (2011) ikan ini biasanya mencapai matang gonad (TKG IV) setelah berukuran di atas $18 \mathrm{~cm}$ dengan berat lebih dari 60 gram. Namun pada pada penelitian ini ukuran diatas $18 \mathrm{~cm}$ dengan berat di atas 60 gram jumlahnya sangat sedikit sekali. Lambak pipih yang berukuran lebih besar antara 20,1 - 30,0 $\mathrm{cm}$ biasa tertangkap dengan jaring ukuran 2 sampai 3,5 inch, namun jumlahnya sangat sedikit sehingga bisa mengganggu proses rekruitmen ikan ini karena ukuran yang lebih besar biasanya merupakan caloncalon induk yang akan berkembang biak nantinya.

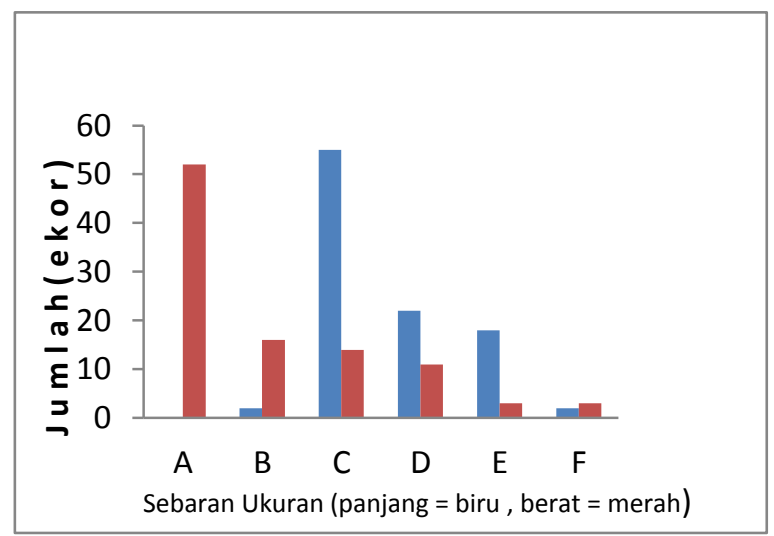

Gambar 3. Sebaran ukuran panjang dan berat ikan lambak pipih 
Keterangan : Ukuran panjang

Ukuran berat

$$
\begin{aligned}
& \mathrm{A}=0,1-5,0 \mathrm{~cm} \\
& \mathrm{~A}=1-30 \underset{\text { gram }}{\mathrm{B}=5,1-10,0 \mathrm{~cm}} \\
& \mathrm{~B}=31-60 \underset{\text { gram }}{\mathrm{C}=10,1-15,0 \mathrm{~cm}} \\
& \mathrm{C}=61-90 \text { gram } \\
& \mathrm{D}=15,1-20,0 \mathrm{~cm} \\
& \mathrm{D}=91-120 \text { gram } \\
& \mathrm{E}=20,1-25,0 \mathrm{~cm} \\
& \mathrm{E}=121-150 \underset{\text { gram }}{\mathrm{F}=25,1-30,0 \mathrm{~cm}} \\
& \mathrm{~F}=151-180 \text { gram }
\end{aligned}
$$

\section{Hubungan panjang-berat}

Analisis hubungan panjang-berat yang dilakukan terhadap ikan lambak pipih, mendapatkan persamaan panjang-berat : $\mathrm{W}$ $=0,013 \mathrm{~L}^{2,901}$ (Gambar 4). Setelah dilakukan uji t pada tingkat signifikasi 95 $\%$, ternyata nilai $\mathrm{b}$ mempunyai (t.hitung $>$ t.tabel) yang berarti nilai $b<3$. Maka dapat dikatakan bahwa ikan lambak pipih mempunyai pola pertumbuhan yang allometrik negatif yang berarti pertumbuhan panjangnya lebih cepat dari pada pertumbuahan berat. Di Waduk Kotopanjang Kabupaten Kampar Riau Suryaningsih (2000) juga mendapatkan pola pertumbuhan yang sama terhadap ikan ini. Namun Bakhris (2008) mendapatkan hasil yang berbeda yaitu pola pertumbuhan yang allometrik positif dengan nilai $b>3$. Adanya perbedaan ini sebetulnya adalah hal yang wajar karena pertumbuhan ikan dipengaruhi oleh bermacam faktor antara lain : jumlah dan ukuran makan yang tersedia, jumlah ikan yang menggunakan sumber makanan, suhu, oksigen terlarut, kualitas air, umur ikan dan tingkat kematangan gonad (Effendie, 1992). Selain itu pertambahan berat ikan tidak hanya disebabkan pertambahan panjang, tetapi juga disebabkan pertambahan tinggi badan ikan (Mulfizar et al., 2012).
Berdasarkan nilai $\mathrm{b}<3=$ Allometri negatif yang berarti panjang ikan ini lebih cepat dari pada berat didapatkan nilai $\mathrm{r}^{2}=$ 0,981 yang mendekati angka 1, ini memperlihatkan bahwa antara panjang dan berat memiliki hubungan yang signifikan, yang menunjukan korelasi yang kuat dan positif antara keduanya (Walpole, 1992).

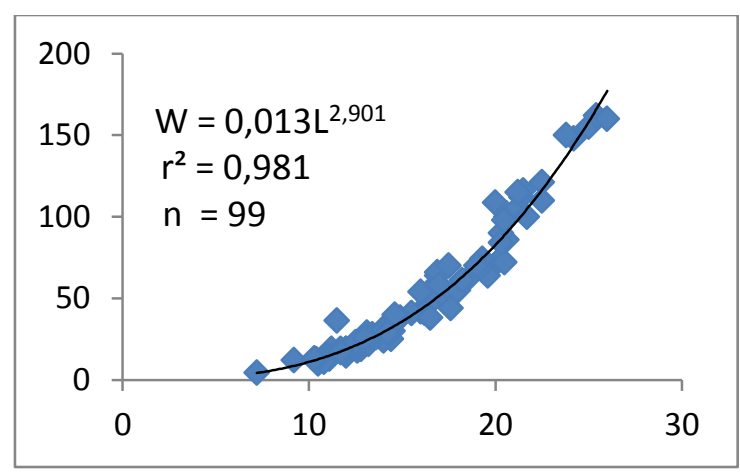

Gambar 4. Hubungan panjang-berat ikan lambak pipih

\section{Pakan alami}

Pemeriksaan terhadap isi usus dan lambung ikan lambak pipih, diketahui bahwa pakan alaminya terdiri dari makrofita (tumbuh-tunbuhanan air) sebanyak 49,9 \% sebagai pakan utama (Gambar 5). Pakan pelengkapanya terdiri dari phytoplankton 22,6\% (Chlorophyceae $10,4 \%$; Bacillariophyceae $8,1 \%$ dan Cyanophyceae 4,1\%, serta detritus $17,4 \%$. Pakan tambahannya berupa Protozoa 0,8 $\%$; Rotifera 0,5 \% dan Crustaceae 0,4\% dan bagian yang tak teridentifikasi $8,4 \%$ (Asyari \& Fatah, 2011). Dengan demikian ikan ikan lambak pipih atau motan digolongkan ke dalam kelompok ikan herbivora atau pemakan tumbuhan.

Menurut Apriliati (2007), ikan motan atau lambak pipih adalah pemakan plankton (plankton feeder) dan detritus (detritus feeder). Hasil penelitian Pulungan (1999) menunujukkan makanan yang paling banyak dikonsumsi ikan ini adalah detritus 53,5 - 67,6 \% dan phytoplankton 21,5 26,1 \%. Menurut Andri (2006), makanan 
yang terdapat di saluran pencernaan ikan motan atau lambak pipih terdiri dari phytoplankton yaitu Bacillariophyta, Chlorophyta, Chrysophyta, Cyanophyta dan Euglenophyta, makrophyta dan zooplankton yang terdiri dari Protozoa, Rotifera, Copepoda dan Cladocera. Lammens \& Hoogenboezem (1981) mengatakan bahwa, semua saluran pencernaan ikan telah disesuaikan dengan makanan yang dikonsumsi oleh ikan tersebut, agar proses mencerna makanan dapat berlangsung optimum. Ikan herbivora memiliki saluran pencernaan yang lebih panjang dibandingkan ikan yang bersifat omnivora dan karnivora karena jenis makanan yang dimakan seperti tumbuh-tumbuhan dan lainnya lebih susah hancur sehingga membutuhkan waktu yang lebih lama untuk mencernanya.

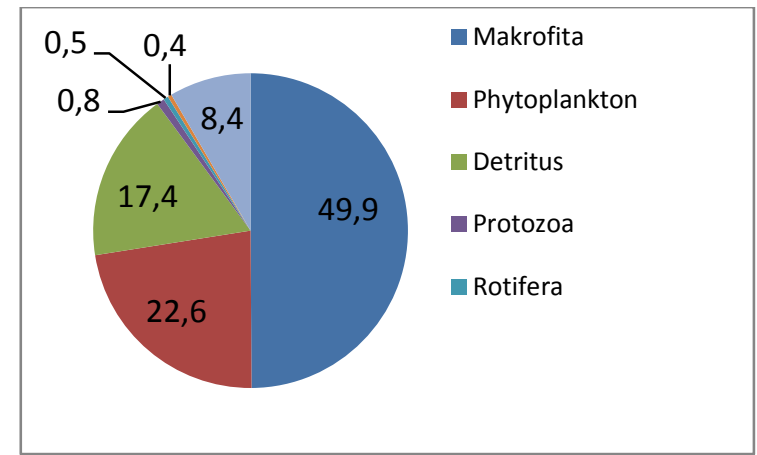

Gambar 5. Pakan alami ikan lambak pipih di Sungai Batanghari

\section{KESIMPULAN}

Ikan lambak pipih yang banyak tertangkap di Sungai Batanghari relatif berukuran kecil, sehingga dikhawatirkan akan mengganggu proses rekruitmen yang bisa mengakibatkan langkanya ikan tersebut.

Hubungan panjang-berat ikan lambak pipih mengikuti pola pertumbuhan allometrik negatif dengan kebiasaan makan bersifat herbivora, mengalami pertumbuhan yang cukup baik di Sungai Batanghari.

\section{UCAPAN TERIMA KASIH}

Makalah ini merupakan kontribusi dari kegiatan penelitian kajian tingkat degradasi dan potensi sumberdaya ikan di Sungai Batanghari Jambi tahun anggaran 2015 yang didanai APBN di Balai Penelitian Perikanan Perairan Umum Palembang. Terima kasih terhadap Bapak Drs. Asyari yan telah membantu mengumpulkan data penelitian dan pengolahan data, dan semua anggota tim dalam pengumpulan data

\section{DAFTAR PUSTAKA}

1. Andri, R. J. 2006. Analisisi isi saluran pencernaan ikan famili Cyprinidae yang memanfaatkan diatom di sekitar keramba di Waduk pembangkit listrik tenaga air Kortopanjang, Provinsi Riau. Fakultas Perikanan dan Ilmu Kelautan Universitas Rioau Pekanbaru. Tidak diterbitkan. 119 pp

2. APHA. 1980. Standard method for the examination of water and wastewater. $15^{\text {th }}$ Edition. American Public Health Assosiation. Washington.D.C. 1134 pp.

3. Aprilianti, R. 2007. Hubungan kelimpahan phytoplankton dengan jumlah ikan motan (Thynnichthys polylepis) di waduk pembangkit listrik tenaga air Kotopanjang. Fakultas Perikanan dan Ilmu Kelautan Universitas Riau Pekanbaru. 55 pp.

4. Asyari. 2011. Kegiatan dan evaluasi penangkapan ikan di sungai Kapuas Kalimantan Barat. Prosiding Forum Perairan Umum Indonesia ke-8. Balai Penelitian Perikanan 
Perairan Umum, Badan Penelitian dan pengmbangan Kelautan dan Perikanan. Hal: 303317.

5. Asyari \& k, Fatah. 2011. Kebiasaan makan dan biologi reproduksi ikan motan (Thynnichthys polylepis) di Waduk Kotopanjang, Riau. Bawal, Widya Riset Perikanan Tangkap. Pusat Penelitian Pengelolaan Perikanan dan Konservasi Sumberdaya Ikan. Badan Penelitian dan Pengembangan Kelautan dan Perikanan KKP. Vol. 3(4) Hal 217224.

6. Bakhris, V. D. 2008. Aspek Reproduksi Ikan Motan (Thynnichthys polylepis Bleeker, 1860) di Rawa Banjiran Sungai Kampar Kiri, Riau. Fakultas Perikanan dan Ilmu Kelautan. Bogor: Institut Pertanian Bogor. 47 hal.

7. Effendi, H. 2003. Telaah Kualitas Air Bagi Pengelolaan Sumber Daya dan Lingkungan Perairan. Kanius; Yogyakarta.

8. Froese, R. and D. Pauly. 2015. Editors FishBase.World Wide Web electronic publication.www.fishbase.org.

9. Froese, R. and D. Pauly. 2015. Editors FishBase.World Wide Web electronic publication.www.fishbase.org.

10. Hamidy, R., M. Ahmad., T. Dahril., H. Alawi., M.M. Siregar \& C.P. Pulungan. 1983. Identifikasi dan inventarisasi jenis ikan di Sungai Siak, Riau. Pusat Penelitian Universitas Riau. Pekanbaru. 63 pp.

11. Kaban, S., Asyari, K. Fatah., M. Marini, T.N.M.Wulandari., Burnawi., Dody H. Nasution \& Mersi. 2015. Kajian tingkat dergradasi dan potensi sumber daya ikan di Sungai Batanghari, Jambi. Laporan Teknis, Balai Penelitian Perikanan Perairan Umum Palembang.

12. Kottelat, M; A.J Whitten; S.N Kartikasari dan S. Wirjoatmodjo, 1993. Freshwater Fishes of Western Indonesia and Sulawesi (Ikan air tawar Indonesia bagian Barat dan Sulawesi). Periplus Edition-Proyek EMDI. Jakarta.

13. Lammens, E.H.R.R \& W. Hoogenboezem. 1981. Diets and feeding behavior. InWinfield, I.J \& J.S. Nelson (eds) : Cyprinid Fishes : Systematics, Biology and Exploitation. Chapman \& Hall. London. 353 - 367.

14. Merrit, R.W \& K. W. Cummins. 1996. An introduction to the aquatic insect of North America.

15. Mulfizar., Z.A. Muchlisin \& I. Dewiyanti. 2012. Hubungan panjang-berat dan faktor kondisi tiga jenis ikan yang tertangkap di perairan kuala Gigieng, Aceh Besar, Provinsi aceh. Jurnal Depik, Fakultas Kelautan dan Perikanan Universitas Syiah kuala, Banda aceh, Vol.1 (1) : 1-9.

16. Needham, J.G \& D.R Needham. 1962. Freshwater biology. Holden Day Inc, Sanfransisco, $108 \mathrm{pp}$.

17. Nurdawati, S. 2010. Penyebaran ikan di perairan rawa banjiran Danau Teluk hubungannya dengan kondisi lingkungan perairan. Prosiding Seminar Nasional Biologi, 2010. Fakultas Biologi UGM Yogyakarta. Hal : 264 - 274.

18. Nurdawati, S. 2013. Fauna ikan di perairan rawa banjiran Sungai Batanghari, Jambi. Seminar Nasional Ikan ke V. November 2013. Published.

19. Pennak, R.W. 1978. Freshwater invertebrates of United Stated. Second Edition, A Wellow Inter Science Publication. Jhon Willey and Sons. New York.803 pp

20. Pulungan, C. P. 1999. Biologi reproduksi ikan motan (Thynnichthys polylepis) dari waduk pembangkit listrik tenaga air Kotopanjang di sekitar Desa Gunung Bungsu, Kecamatan XIII, Koto Kampar, Riau. Jurnal Terubuk. 31 : 36 - 40. 
21. Suryaningsih. 2000. Beberapa Aspek Biologi Ikan Motan (Thynnichthys polylepis, Blkr) dari Waduk PLTA di Sekitar Desa Gunung Bungsu Propinsi Riau, Pekanbaru: Fakultas Perikanan dan Ilmu Kelautan, Universitas Riau.

22. Walpole, R. E. 1992. Pengantar Statistika (Diterjemahkan oleh Bambang Sumantri). Edisi Ketiga. PT. Gramedia. Jakarta. 515 pp. 